\title{
A STUDY ON THE EFFECT OF NOISE AND VIBRATION ON OPERATORS' READABILITY TASK PERFORMANCE IN A MOBILE DRIVING ENVIRONMENT
}

\author{
Iqbal Ahmed Khan \\ Department of Mechanical Engineering, \\ Lingaya's Institute of Management \& Technology, Nachauli, \\ Faridabad, Haryana, India

\section{Z. Mallick*} \\ School of Mechanical Engineering, Universiti Sains Malaysia, \\ 14300 Nibong Tebal, Penang, Malaysia
}

\section{Zahid A. Khan}

Department of Mechanical Engineering, Faculty of Engineering \& Technology, Jamia Millia Islamia, New Delhi, India

Received 20 December 2005

\begin{abstract}
This paper presents a study in which the effect of noise and vibration on the task performance in a mobile driving environment is experimentally investigated. A readability kind of task, where a reading material was presented to the operators on a laptop screen was considered and the operators performed the task in a sitting posture without their back supported with the backrest of the seat. The task performance was measured in terms of mean number of characters read per minute by the operators, which served as data for statistical analysis. Results of the study showed that noise and vibration were statistically significant. The interaction between gender and vibration was also found to be significant. The presence of noise and vibration in a mobile environment decreased the operators' task performance. The results of the simple main effect analysis indicated that the gender was statistically significant for the last two levels of vibration. However the equivalent acceleration of vibration was found statistically significant for males and females. The findings are in line with previous researches that showed negative significant effect of noise and vibration on operators' task performance.
\end{abstract}

Keywords: Readability task performance, Noise, Equivalent acceleration of vibration, Mobile environment.

\section{INTRODUCTION}

The use of newer and portable versions of computers by executives and other professionals in a

\footnotetext{
* Corresponding author e-mail: zmallick2002@yahoo.co.in
} 
mobile environment has increased manifolds in recent times. The mobile computing has exposed the operators to various environmental stresses. Notable among them are noise and vibration to which the operators are subjected. Apart from these, other factors like sitting posture, gender, age etc. may influence operator's task performance. Studies have shown that the short-term whole-body vibration exposure could affect the visual performance, depending on the vibration frequency and the sitting posture [1]. Manual control performance was also found to be disrupted due to whole body vibration [2]. The visual cortical activity has been shown to diminish substantially when the subjects were exposed to large acoustic sound [3]. Noise negatively influenced the performance in carrying out focused attention kind of task [4]. Literature reviewed on the topic revealed that though many studies have been conducted in the past to assess the effect of environmental stresses separately, researches on the combined effect of noise and vibration in a mobile computing environment were a few. Harris and shoenberger [5] showed adverse effects on performance when the task was conducted in the presence of combined noise and vibration. The noise and vibration could adversely affect subjective operator workload without affecting objective task performance [6]. As far as the effect of posture was concerned, the whole-body vibration was found to have significant effect on seated subjects [7]. The psychological responses of human beings to whole-body vibration were also found to be affected greatly by the posture [8]. Combined exposure to noise and vibration could lead to the increased instability of the body upright posture. Hinz et al. [9] observed that the backrest contact and posture should be an important factor for the assessment of whole-body vibration. Working on VDU was found to be more taxing for females than males[10] as they showed greater prevalence of musculoskeletal symptoms. Keeping this in mind, the present study was designed to investigate the effect of noise and vibration on readability task performance where reading materials were presented to the operators on the screen of a laptop computer and the operators performed the task in a sitting posture with their back supported with the back support. The readability task was performed by the operators under varying levels of noise and vibration in a mobile driving environment. The following null hypotheses were structured.

1. The varying levels of noise did not affect the readability task performance of male and female operators in a mobile driving environment.

2. There was no effect of equivalent level of vibration acceleration on operators, performing readability task.

3. There was no effect of gender (male and female) when the readability task was performed.

\section{METHOD}

\subsection{Subjects}

Fourteen subjects ( 7 males and 7 females) participated in this study. Their age ranged from 22 years to 32 years (mean 26 years; S.D. $= \pm 4.9$ years)

All the subjects had normal vision with no previous history of neuromuscular disorder.

\subsection{Experimental setup}

Experimental investigations were carried out in a vehicle (Maruti-Omni Van), which was given the shape of a mobile research unit. The unit comprised of the following sub-systems (Figure 1):

1. Laptop (Model: ARMADA 1500, Compaq).

2. Sound Level Meter (Model: GA 214, Castle Group Limited, UK).

3. A Vibration Level Meter (Model: VR 5100, ONO SOKKI Co. Ltd., Japan). 
4. The laptop screen angle $\left(120^{\circ}\right)$ was maintained by the subjects.

5. Audio Cassette Player along with cassettes.

6. Reading material in French language.

7. The font was Times New Roman, regular, 14 in size having automatic color and characters were normal spacing with blue background of screen.

8. A sitting posture without backrest was maintained by the operators.

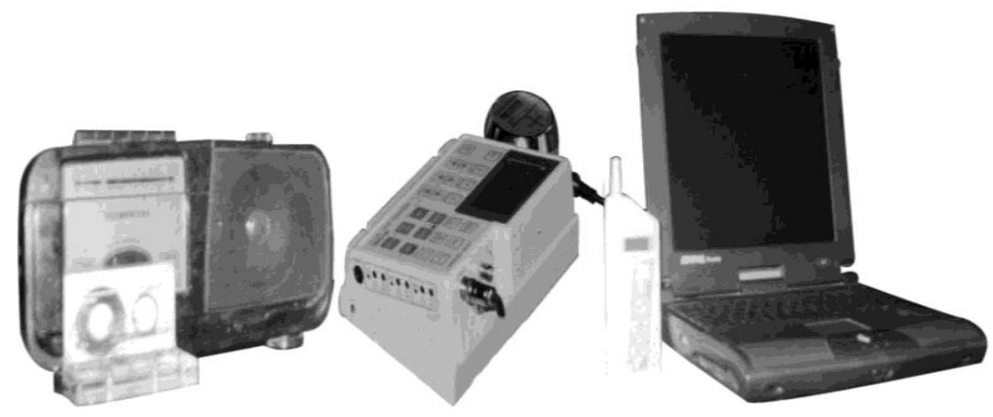

Fig. 1: Photographic view of the equipments used in the experimental set up.

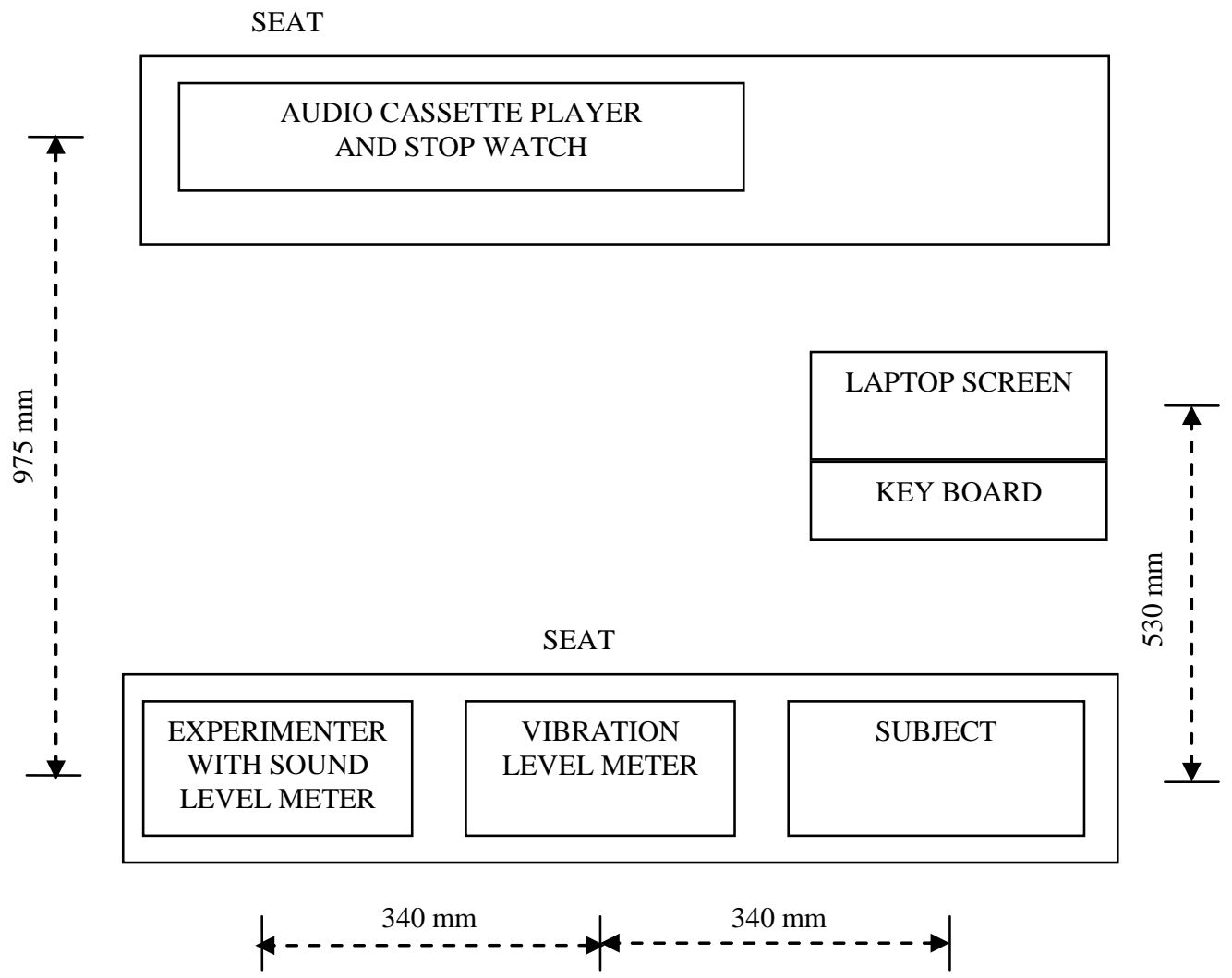

Fig. 2: Schematic diagram of the experimental set up. 
Figure 2 shows the schematic diagram of the experimental set up in which placement of the sub systems and distances between them are depicted. The distances (Figure 2) were suggested by the operators since they were able to perform the assigned task comfortably when the sub systems were placed at these distances. It may be noted that the laptop was kept on the thigh of the subjects while they were performing readability task and the distance from the subject to the laptop screen shown in Figure 2, in fact represents the distance from the subject's eye (Figure 3 (a) and (b)) to the center of the laptop screen. Further, arrangements were also made to avoid glaring of screen.

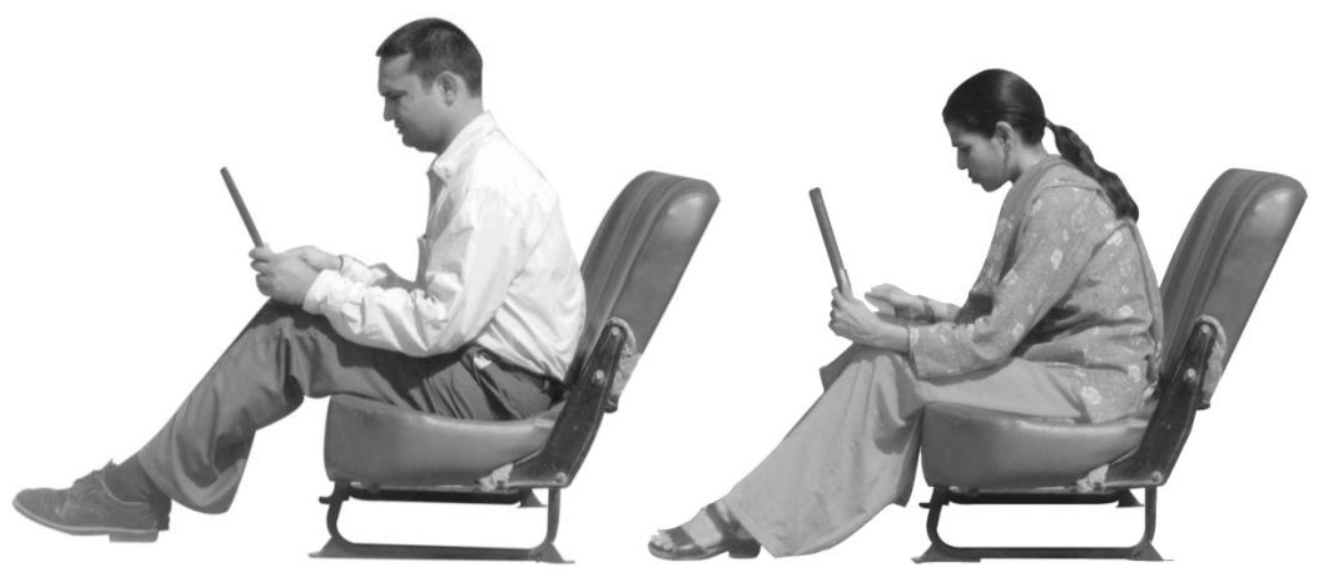

(a)

(b)

Fig. 3: (a) and (b): Male and Female operators performing readability task on laptop at without backrest posture.

\subsection{General experimental procedure}

The following preparatory steps were undertaken before performing the actual experiment.

1. Each subject was briefed about the objective of the experiment.

2. Instructions to be followed while performing the experimental task were given to the subjects.

3. Training sessions were organized for subjects in order to get them familiarized with the task to be performed.

The subject had taken his/her seat in the mobile research unit and all the instructions were imparted. Subsequently, following steps were taken, in that order, for both the training and experimental sessions.

a. The reading material in French language written in English script was presented on the screen of the laptop to the subject by the experimenter.

b. A START signal was given to the subject to start the readability task.

c. The subjects performed the readability task for duration of 20 minutes and the task performance was measured in terms of mean number of characters read per minute (MNCRPM) by the subject.

d. A STOP signal was given to the subjects to indicate them to stop the readability task. 
The experiments were conducted under varying levels of noise and equivalent vibration. The levels of noise viz $80 \mathrm{dBA}$ Leq, $90 \mathrm{dBA}$ Leq, and $100 \mathrm{dBA}$ Leq were selected. The equivalent level of vibration was also taken at three levels $\left(0.45,0.94\right.$, and $\left.1.71 \mathrm{~m} / \mathrm{s}^{2}\right)$. While performing the experimental task the levels of equivalent noise and vibration in the mobile environment were kept at a pre-specified value by constantly monitoring their levels. The pre-specified levels of noise were maintained by manipulating the volume regulator of the audio cassette player and they were measured near the ear of the subjects. The level of vibration was also kept same in $x$, $\mathrm{y}$ and $\mathrm{z}$ directions by manipulating the speed of the vehicle. Average time for each experimental session was of the order of 20 minutes. A rest period of 30 minutes was provided to the subjects before carrying out another set of experiment.

\subsection{Noise and vibration levels}

A pilot study was carried out to determine the different levels of equivalent noise and vibration acceleration in the $\mathrm{x}, \mathrm{y}$ and $\mathrm{z}$ directions to which operators were subjected while moving in driving environment .It was observed that the noise level varied from $80 \mathrm{dBA}$ Leq to $100 \mathrm{dBA}$ Leq and the level of equivalent vibration was in between 0.45 to $1.71 \mathrm{~m} / \mathrm{s}^{2}$. Total equivalent acceleration of vibration was calculated as per the recommendations of Standard No. ISO 2631 1:1997 [11]. In light of the above discussion, three equivalent levels of noise i.e. 80, 90 and 100 $\mathrm{dBA}$ Leq and three equivalent levels of acceleration of vibration were set at $0.45,0.94$ and $1.71 \mathrm{~m} / \mathrm{s}^{2}$

\subsection{Task performance}

Subjects read the material (French script written in English) presented to them on a laptop screen as per the instructions imparted to them. The mean number of characters read per minute (MNCRPM) by the operator was taken as a measure of task performance. It was ensured that the subject did not commit mistakes of any kind.

\subsection{Stimuli and the experimental task}

A stimulus in the form of text was presented on full screen of the laptop to the subjects. The text presented has no literal meaning. It was in French language. To avoid any learning effect, four different texts in French were provided to them. This feature minimized the difference between subjects from proficiency of English language view point.

\subsection{Statistical analysis}

A three factor ANOVA was carried out to determine the effects of parameters under investigation. The independent variables taken were organismic variable gender (male and female), noise (80 dBA Leq, $90 \mathrm{dBA}$ Leq and $100 \mathrm{dBA}$ Leq) and vibration (0.45, 0.94 and 1.71 $\mathrm{m} / \mathrm{s}^{2}$ ). The dependent variable was readability task performance, which was measured in terms of mean number of characters read per minute (MNCRPM).

\subsection{Noise recording and measurement}

The road traffic noise was recorded in a cassette through an audiocassette recorder/player. During experimental session the noise level was maintained at three levels viz. $80 \mathrm{dBA}$ Leq, 90 $\mathrm{dBA}$ Leq and $100 \mathrm{dBA}$ Leq by regulating the volume knob of the audio cassette recorder/player. The measurement of equivalent level of noise was done with the help of a Sound Level Meter (Model: GA 214, Castle Group Limited, UK). The Sound Level Meter was calibrated prior to measurements. The measuring levels range of the equipment and the measuring frequency range (including microphone) were $35 \mathrm{dBA}$ to $140 \mathrm{dBA}$ and $20 \mathrm{~Hz}$ to $8 \mathrm{kHz}$. 


\subsection{Vibration measurement}

The vibration level meter (VR 5100, ONO SOKKI Co. Ltd. Japan) based on Japanese Industrial Standards (JIS C 1510-1976) and the measurement law of Japan was used to measure the equivalent level of vibration acceleration in each $\mathrm{x}, \mathrm{y}$ and $\mathrm{z}$ direction. The vibration pickup (NP7210) with three independent shear type piezoelectric elements for detecting signals was placed on the seat of the Maruti Van on a specially prepared hard disc as per the recommendations of Standard No. ISO 2631-1:1997 [11]. The vibration acceleration levels were measured with respect to the standard biodynamic coordinate system according to ISO 2631-1:1997.The vibration level meter was calibrated in the $\mathrm{x}, \mathrm{y}$ and $\mathrm{z}$ directions prior to measurements. The measuring level range of the equipment and the measuring frequency range were 30 to $120 \mathrm{~dB}$ and 1 to $90 \mathrm{~Hz}$ respectively. To check the suitability of the basic evaluation method, the crest factor was calculated for the $\mathrm{x}, \mathrm{y}$ and $\mathrm{z}$ directions. According to ISO 2631-1:1997, the crest factor is defined as the modulus of the ratio of the maximum instantaneous peak value of the frequency weighted acceleration signal to its root mean square (r.m.s) value. The peak shall be determined over the duration of measurement. The crest factor values obtained for the $\mathrm{x}, \mathrm{y}$ and $\mathrm{z}$ directions were within the limit prescribed by ISO 2631-1:1997. As per ISO 2631-1:1997 recommendations, for vibration with crest factors below or equal to 9 , the basic evaluation method is normally sufficient.

\section{RESULTS}

In this study, the effect of noise and vibration on operators' (male and female) readability task performance on laptop screen in a mobile driving environment was investigated. The results of the analysis of variance (ANOVA) carried out on the data collected showed that the effect of noise, vibration, were statistically significant. The interaction of gender with vibration was found to be statistically significant (Table 1). The significant interaction gender and vibration necessitated an analysis of simple main effects. The results of the simple main effects analysis (Table 2) indicated that the gender was statistically significant for the last two levels of vibration acceleration. Also the equivalent acceleration of vibration emerged to be statistically significant for both males and females.

In the next phase of analysis, mean levels of readability task performance (MNCRPM) for male, female, male and female operators were computed independently for different levels of noise and equivalent acceleration of vibration as shown in Table 3, 4 and 5 respectively. The relationship of task performance and different levels of vibration acceleration (Figure 4, 6 and 8), and the relationship of task performance and different levels of noise (Figure 5, 7 and 9) were further explored through the regression analysis. It was found that the equation of best fit was based on linear function.

The governing equations for task performance of male operators versus vibration acceleration level for varying noise levels (Figure 4) were obtained as follows:

(i) For noise level of $80 \mathrm{dBA}$ Leq

$\mathrm{TP}_{1}=92.77-7.15 \mathrm{~V}$

correlation coefficient $\left(r_{1}\right)=0.9973$

(ii) For noise level of $90 \mathrm{dBA}$ Leq

$\mathrm{TP}_{2}=86.17-6.1 \mathrm{~V}$

correlation coefficient $\left(r_{2}\right)=0.9978$

(iii) For noise level of $100 \mathrm{dBA}$ Leq

$\mathrm{TP}_{3}=76.23-4.5 \mathrm{~V} \quad$ correlation coefficient $\left(\mathrm{r}_{3}\right)=0.9596$ 
Where $\mathrm{TP}_{1}, \mathrm{TP}_{2}$ and $\mathrm{TP}_{3}$ represent the task performance at varying levels of noise and $\mathrm{V}$ is the value of equivalent acceleration of vibration

Table 1: Summary of the analysis of variance pertaining to the effect on operators' (at without backrest posture) readability task performance on laptop screen under varying levels of noise and equivalent acceleration of vibration.

\begin{tabular}{llccc}
\hline Source of variation & df & MS & F & p \\
\hline Between Subjects & 13 & - & - & \\
G (Gender) & 1 & 529.93 & 0.54 & .4765 \\
Subjects within groups (Error-I) & 12 & 982.06 & - & \\
Within Subjects & 112 & - & - & \\
N (Noise level) & 2 & 2097.83 & 37.71 & .0001 \\
Gender x Noise & 2 & 145.90 & 2.62 & .00935 \\
Noise x Subjects within groups (Error-II) & 24 & 55.62 & - & \\
V (Equivalent acceleration of vibration level) & 2 & 2694.41 & 110.29 & .0001 \\
Gender x Vibration & 2 & 194.55 & 7.96 & .0022 \\
Vibration x Subjects within groups (Error-III) & 24 & 24.43 & - & \\
Noise x Vibration & 4 & 12.79 & 1.29 & .2872 \\
Gender x Noise x Vibration & 4 & 19.31 & 1.96 & .1158 \\
Noise x Vibration x Subjects within groups & 48 & 9.85 & - & \\
(Error-IV) & & & & \\
Total & 125 & - & - & \\
\hline
\end{tabular}

Table 2: Analysis of Simple Main Effect of operators (male \& female) performed readability task on laptop screen under varying levels of equivalent acceleration of vibration in a mobile driving environment.

\begin{tabular}{lcrrr}
\hline Source of variation & df & MS & F & p \\
\hline $\mathrm{G}($ Gender) at & & & & \\
Vibration acceleration level ${ }_{1}\left(0.45 \mathrm{~m} / \mathrm{s}^{2}\right)$ & 1 & 43.66 & 1.79 & .1935 \\
Vibration acceleration level $_{2}\left(0.94 \mathrm{~m} / \mathrm{s}^{2}\right)$ & 1 & 288.12 & 11.79 & .0022 \\
Vibration acceleration level ${ }_{3}\left(1.71 \mathrm{~m} / \mathrm{s}^{2}\right)$ & 1 & 626.43 & 25.65 & .0001 \\
$\mathrm{~V}($ Equivalent acceleration of vibration level) at & & & & \\
$\mathrm{At} \mathrm{G}_{1}$ (Male) & 2 & 739.92 & 30.29 & .0001 \\
$\mathrm{At}_{2}$ (Female) & 2 & 2463.42 & 100.9 & .0001 \\
\hline
\end{tabular}

The governing equations for task performance of male subjects and noise level for different levels of equivalent acceleration of vibration (Figure 5) were obtained as follows:

(iv) For equivalent acceleration of vibration level of $0.45 \mathrm{~m} / \mathrm{s}^{2}$ 
$\mathrm{TP}_{4}=93.03-7.1 \mathrm{~N} \quad$ correlation coefficient $\left(\mathrm{r}_{4}\right)=0.9834$

(v) For equivalent acceleration of vibration level of $0.94 \mathrm{~m} / \mathrm{s}^{2}$

$\mathrm{TP}_{5}=84.43-5.3 \mathrm{~N} \quad$ correlation coefficient $\left(\mathrm{r}_{5}\right)=0.9942$

(vi) For equivalent acceleration of vibration level of $1.71 \mathrm{~m} / \mathrm{s}^{2}$

$\mathrm{TP}_{6}=75.9-4.45 \mathrm{~N} \quad$ correlation coefficient $\left(\mathrm{r}_{6}\right)=0.9818$

Where $\mathrm{TP}_{4}, \mathrm{TP}_{5}$ and $\mathrm{TP}_{6}$ represent the task performance at varying levels of vibration acceleration and $\mathrm{N}$ is the level of noise.

Table 3: Readability task performance (MNCRPM) of male operators' on laptop screen under the impact of varying levels of noise and equivalent acceleration of vibration.

\begin{tabular}{cccc}
\hline Noise levels (dBA Leq) & \multicolumn{3}{c}{ Equivalent Acceleration of Vibration Levels $\left(\mathrm{m} / \mathrm{s}^{2}\right)$} \\
& $\mathrm{V}_{1}$ & $\mathrm{~V}_{2}$ & $\mathrm{~V}_{3}$ \\
& 0.45 & 0.94 & 1.71 \\
\hline 80 & 85.4 & 78.9 & 71.1 \\
90 & 79.9 & 74.3 & 67.7 \\
100 & 71.2 & 68.3 & 62.2 \\
\hline
\end{tabular}

Table 4: Readability task performance of female operators' (without backrest posture) on laptop screen under the impact of varying levels of noise and equivalent acceleration of vibration.

\begin{tabular}{cccc}
\hline Noise levels (dBA) & \multicolumn{4}{c}{ Equivalent } & Acceleration of Vibration Levels $\left(\mathrm{m} / \mathrm{s}^{2}\right)$ \\
& $\mathrm{V}_{1}$ & $\mathrm{~V}_{2}$ & $\mathrm{~V}_{3}$ \\
& 0.45 & 0.94 & 1.71 \\
\hline 80 & 88.2 & 78.3 & 69.4 \\
90 & 78.4 & 64.7 & 58.1 \\
100 & 71.9 & 62.7 & 50.3 \\
\hline
\end{tabular}

Table 5: Readability task performance of male and female operators' (without backrest posture) on laptop screen under the impact of varying levels of noise and equivalent acceleration of vibration

\begin{tabular}{cccc}
\hline Noise levels (dBA) & \multicolumn{4}{c}{ Equivalent } & Acceleration of Vibration Levels $\left(\mathrm{m} / \mathrm{s}^{2}\right)$ \\
& $\mathrm{V}_{1}$ & $\mathrm{~V}_{2}$ & $\mathrm{~V}_{3}$ \\
& 0.45 & 0.94 & 1.71 \\
\hline 80 & 173.6 & 157.2 & 140.5 \\
90 & 158.3 & 139.0 & 125.8 \\
100 & 143.1 & 131.0 & 112.5 \\
\hline
\end{tabular}

The task performance model (female subjects) for varying noise levels (Figure 6) were obtained as follows: 
(i) For noise level of $80 \mathrm{dBA}$ Leq

$\mathrm{TP}_{1}=97.43-9.4 \mathrm{~V} \quad$ correlation coefficient $\left(\mathrm{r}_{1}\right)=0.9991$

(ii) For noise level of $90 \mathrm{dBA}$ Leq

$\mathrm{TP}_{2}=87.37-10.15 \mathrm{~V}$

correlation coefficient $\left(\mathrm{r}_{2}\right)=0.9608$

(iii) For noise level of $100 \mathrm{dBA}$ Leq

$\mathrm{TP}_{3}=83.23-10.8 \mathrm{~V} \quad$ correlation coefficient $\left(\mathrm{r}_{3}\right)=0.9927$

Where $\mathrm{TP}_{1}, \mathrm{TP}_{2}$ and $\mathrm{TP}_{3}$ represent the task performance at varying levels of noise and $\mathrm{V}$ is the value of equivalent acceleration of vibration

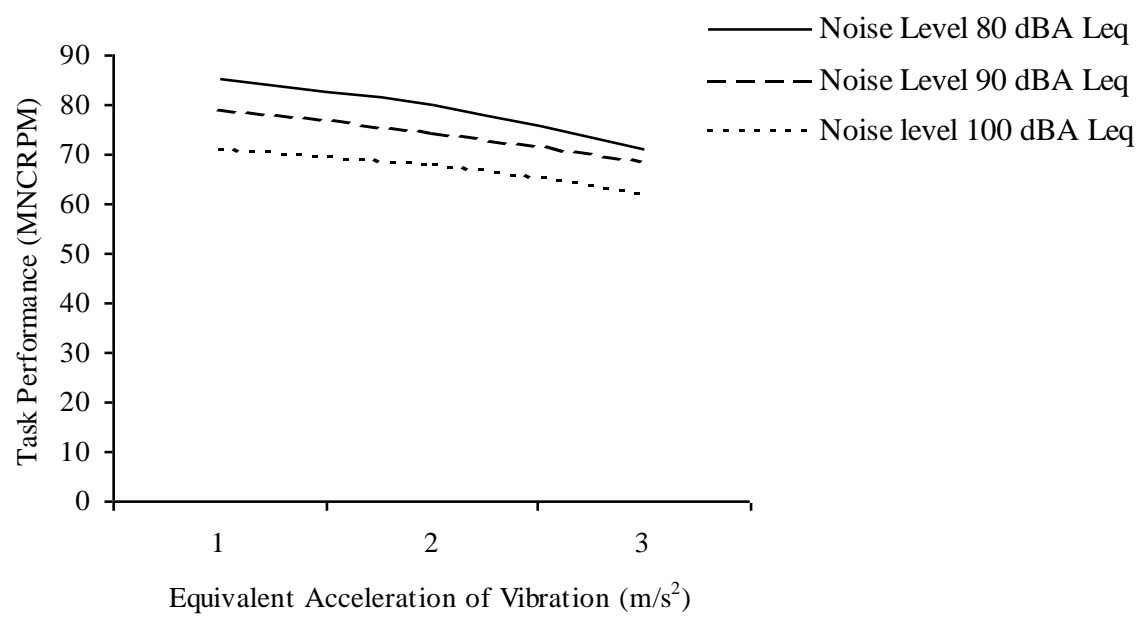

Fig. 4: Relationship between task performance and Equivalent acceleration of vibration at different noise levels for male subjects in a mobile environment.

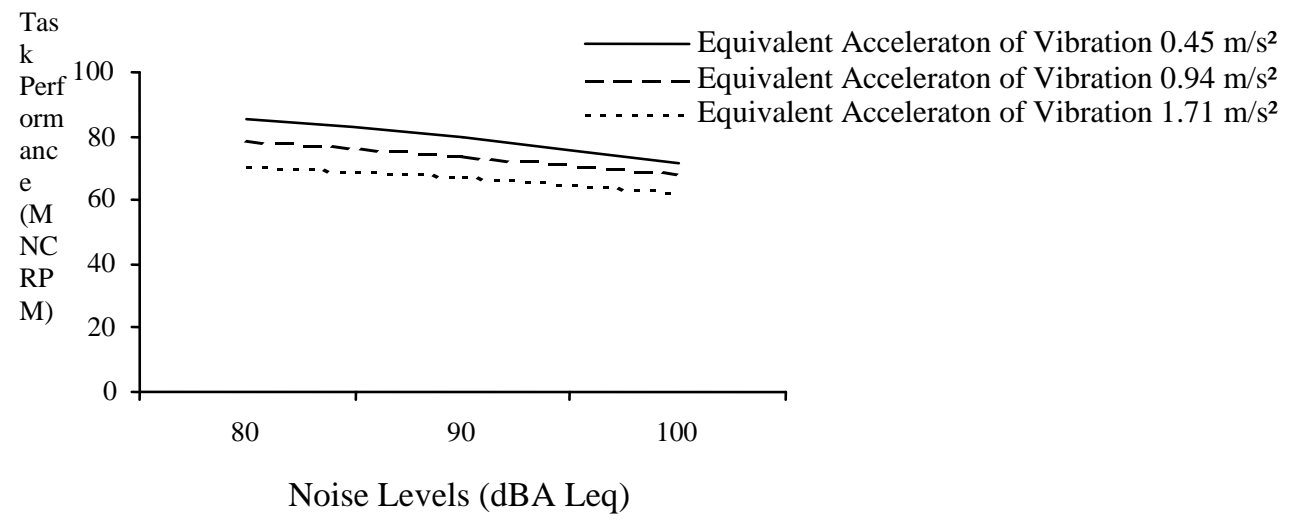

Fig. 5: Relationship between task performance and Equivalent Noise levels at different levels of equivalent acceleration of vibration for male subjects in a mobile environment. 


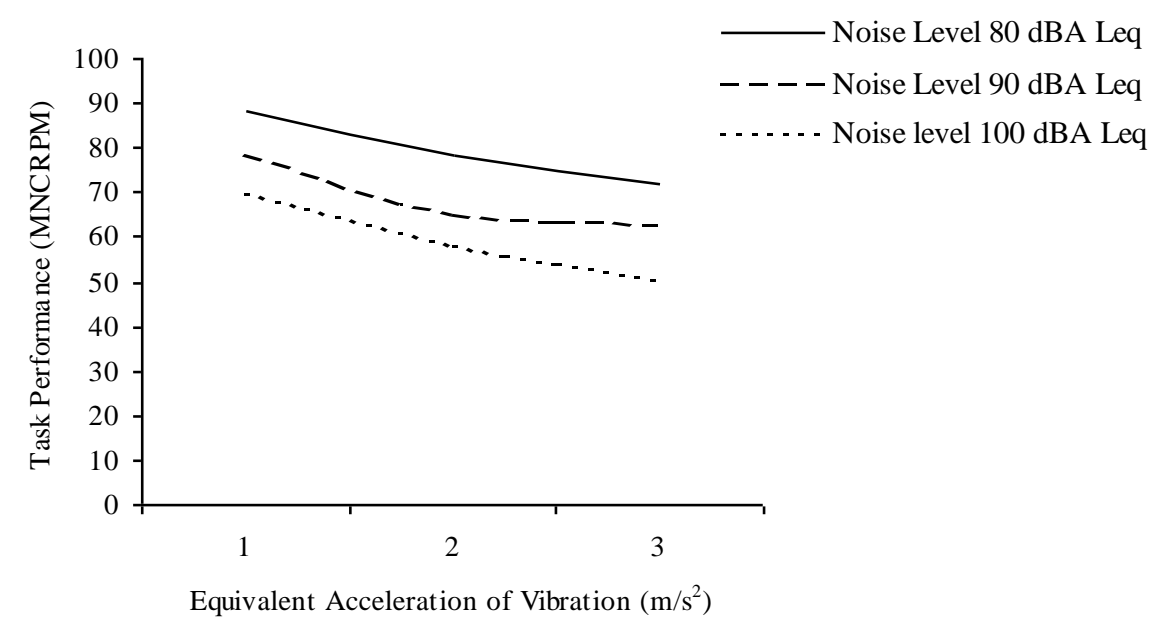

Fig. 6: Relationship between task performance and Equivalent acceleration of vibration at different noise levels for female subjects in a mobile environment.

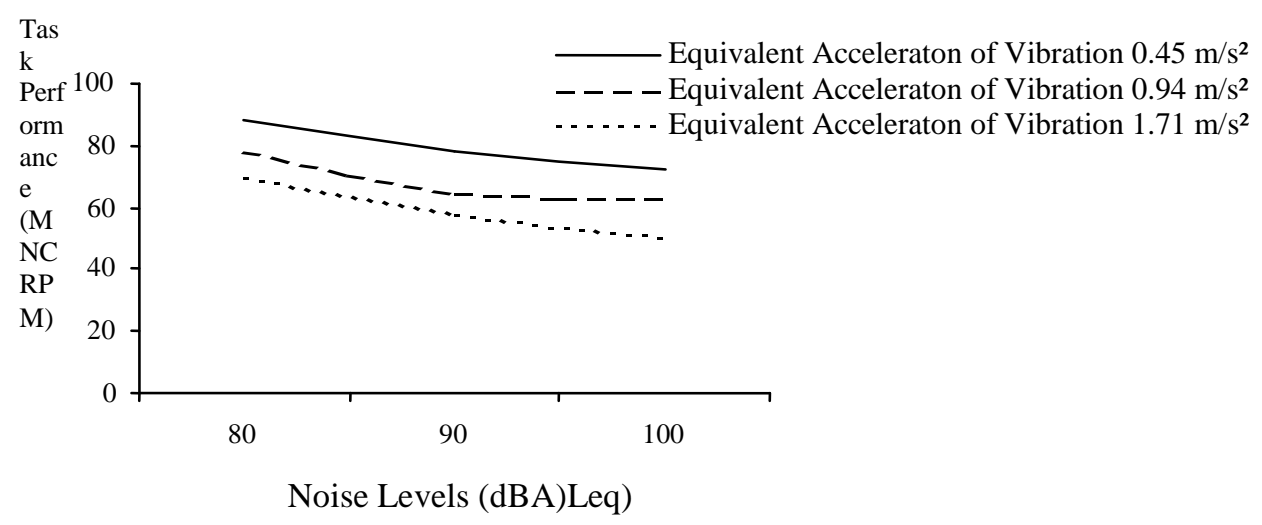

Fig. 7: Relationship between task performance and Equivalent Noise levels at different levels of equivalent acceleration of vibration for female subjects in a mobile driving environment.

The governing equations for task performance of female subjects and noise level for different levels of equivalent acceleration of vibration (Figure 7) were obtained as follows:

(iv) For equivalent acceleration of vibration level of $0.45 \mathrm{~m} / \mathrm{s}^{2}$

$\mathrm{TP}_{4}=95.8-8.15 \mathrm{~N} \quad$ correlation coefficient $\left(\mathrm{r}_{4}\right)=0.9865$

(v) For equivalent acceleration of vibration level of $0.94 \mathrm{~m} / \mathrm{s}^{2}$

$\mathrm{TP}_{5}=84.17-7.8 \mathrm{~N}$

correlation coefficient $\left(\mathrm{r}_{5}\right)=0.8444$

(vi) For equivalent acceleration of vibration level of $1.71 \mathrm{~m} / \mathrm{s}^{2}$

$\mathrm{TP}_{6}=78.37-9.55 \mathrm{~N} \quad$ correlation coefficient $\left(\mathrm{r}_{6}\right)=0.9889$

Where $\mathrm{TP}_{4}, \mathrm{TP}_{5}$ and $\mathrm{TP}_{6}$ represent the task performance at varying levels of vibration acceleration and $\mathrm{N}$ is the level of noise. 


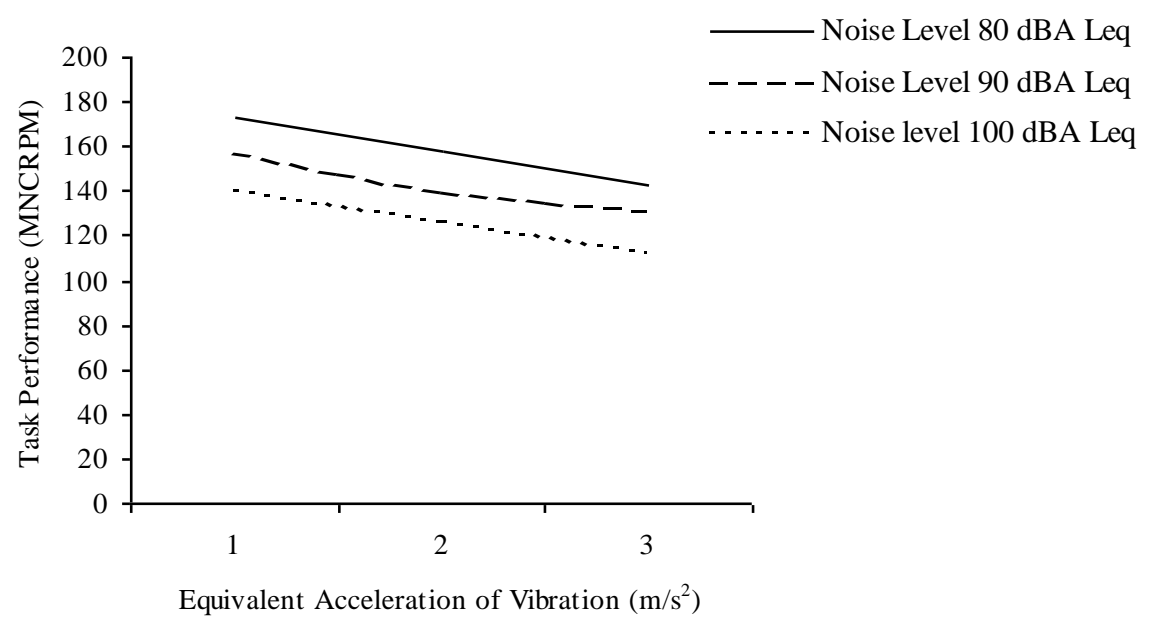

Fig. 8: Relationship between task performance and Equivalent acceleration of vibration at different noise levels for male and female subjects in a mobile environment.

The task performance model (male \& female subjects) for varying noise levels (Figure 8) was obtained as follows:

(i) For noise level of $80 \mathrm{dBA}$ Leq

$\mathrm{TP}_{1}=190.2-16.55 \mathrm{~V} \quad$ correlation coefficient $\left(\mathrm{r}_{1}\right)=1.0$

(ii) For noise level of $90 \mathrm{dBA}$ Leq

$\mathrm{TP}_{2}=173.53-16.25 \mathrm{~V} \quad$ correlation coefficient $\left(\mathrm{r}_{2}\right)=0.9884$

(iii) For noise level of $100 \mathrm{dBA}$ Leq

$\mathrm{TP}_{3}=159.47-15.3 \mathrm{~V} \quad$ correlation coefficient $\left(\mathrm{r}_{3}\right)=0.9856$

Where $\mathrm{TP}_{1}, \mathrm{TP}_{2}$ and $\mathrm{TP}_{3}$ represent the task performance at varying levels of noise and $\mathrm{V}$ is the value of equivalent acceleration of vibration

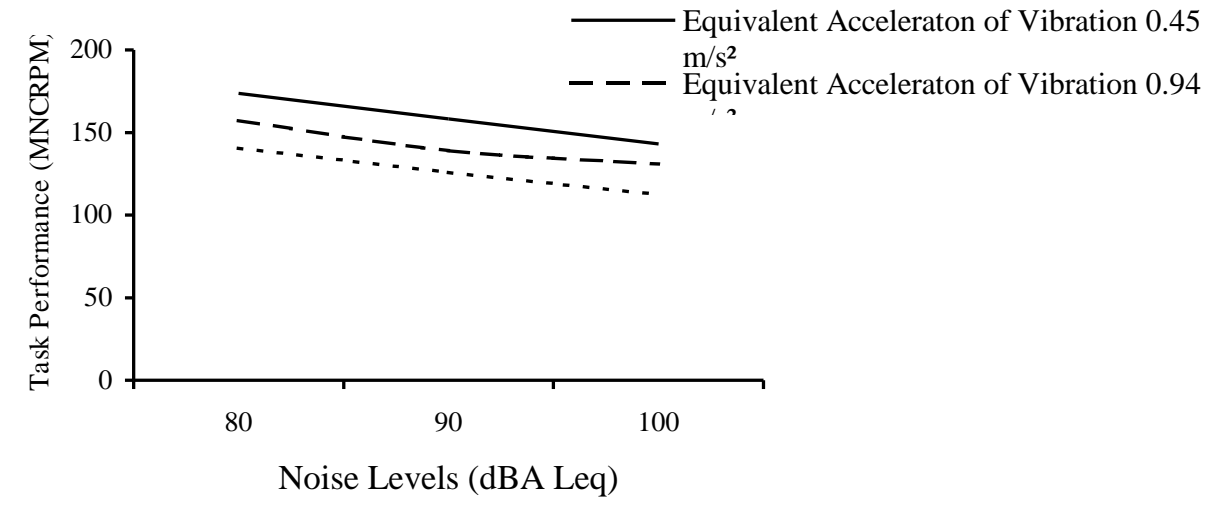

Fig. 9: Relationship between task performance and Equivalent Noise levels at different levels of equivalent acceleration of vibration for male and female subjects in a mobile driving environment. 
The governing equations for task performance of male and female subjects and noise level for different levels of equivalent acceleration of vibration (Figure 9) were obtained as follows:

(iv) For equivalent acceleration of vibration level of $0.45 \mathrm{~m} / \mathrm{s}^{2}$

$\mathrm{HP}_{4}=188.83-15.25 \mathrm{~N} \quad$ correlation coefficient $\left(\mathrm{r}_{4}\right)=1.0$

(v) For equivalent acceleration of vibration level of $0.94 \mathrm{~m} / \mathrm{s}^{2}$

$\mathrm{HP}_{5}=168.6-13.1 \mathrm{~N} \quad$ correlation coefficient $\left(\mathrm{r}_{5}\right)=0.9519$

(vi) For equivalent acceleration of vibration level of $1.71 \mathrm{~m} / \mathrm{s}^{2}$

$\mathrm{HP}_{6}=154.27-14 \mathrm{~N} \quad$ correlation coefficient $\left(\mathrm{r}_{6}\right)=0.9992$

Where $\mathrm{TP}_{4}, \mathrm{TP}_{5}$ and $\mathrm{TP}_{6}$ represent the task performance at varying levels of vibration acceleration and $\mathrm{N}$ is the level of noise.

\section{DISCUSSION}

The hypotheses posed earlier was tested and found to contradict for different levels of noise and equivalent acceleration of vibration. Findings of the present work are supported by many researches. William Taylor et al. [12] found that the random and intermittent noise have negative effects on the easy search task accuracy of subjects comprising both males and females. Bengtsson et al. [13] found that the low frequency noise adversely influenced the performance of female subjects on two tasks sensitive to reduce attention and on a proof reading task. Low frequency noise annoyed the male operators and should be considered in the occupational exposure assessment [14]. Low frequency noise at $50 \mathrm{dBA}$ could be perceived as annoying and adversely affecting mental performance (concentration and visual perception) of male operators [15]. Men and women performance was decreased in spatial ability task as well as in the tasks related to motion sickness [16]. It was also found that noise impaired performance on the focused attention kind of tasks [4].

The results also indicated that the vibration played a dominant role in decreasing the operators' readability task performance on laptop screen in a mobile driving environment. Guedry et al. [17] found that the whole-body angular oscillation of $2.5 \mathrm{~Hz}\left( \pm 20^{\circ}\right.$ peak velocity) degraded the visual search task, but did not produce signs and symptoms of motion sickness with in a 5 minutes exposure. Sherwood and Griffin [18] suggested that the vibration disrupts central cognitive mechanisms utilized during the processing of information in short-term memory. Kato and Hanai [19] showed that the sensitivity at $20 \mathrm{~Hz}$ and $40 \mathrm{~Hz}$ on inclined rigid backrests (inclined at $20^{\circ}$ and $40^{\circ}$ from vertical) was significant and about 1.4 to 1.5 times greater than on a vertical backrest but there was no significant difference between the two contours for inclined backrest. Village et al. [20] also reported the performance impairment due to multiple vibration frequencies. Further, Wells and Griffin [21] indicated a relationship between biodynamic behaviour and visual performance during vibration.

While at the same time interaction between gender and vibration was also found to be statistically significant. This finding gets support from the study of Griffin and Hayward [22] who found that the reading speed of male and female subjects was reduced significantly at frequencies between $1.25 \mathrm{~Hz}$ and $6.3 \mathrm{~Hz}$, with greater impairment at higher magnitudes of vibration. Maximum interference with reading was reported at $4 \mathrm{~Hz}$. Corbridge and Griffin [23] reported that the letter writing speed of male and female passengers was decreased and subjective ratings of writing difficulty increased with increasing vibration magnitude, particularly in the frequency range of $4 \mathrm{~Hz}$ to $8 \mathrm{~Hz}$. Writing difficulty was also increased with increasing duration of vibration. A 10 seconds exposure to $5 \mathrm{~Hz}$ vibration at $2 \mathrm{~m} / \mathrm{s}^{2} \mathrm{r}$.m.s offers extreme difficulty to the subjects in writing work. 


\section{CONCLUSION}

Based on the results of this study as discussed earlier, the following conclusions were drawn:

1. Noise had a significant negative effect on readability task performance in a mobile driving environment.

2. Vehicular vibration had a significant negative effect on readability task performance of the operators' in a mobile driving environment.

3. The interaction between gender and vibration was found to be statistically significant.

\section{REFERENCES}

1. Ishitake, T., Ando, H., Miyazaki, Y., and Matoba, F. (1998), Changes of visual performance induced by exposure to whole-body vibration. Kurume Med J., 45(1), pp. 59-62.

2. McLeod, R.W. and Griffin, M.J. (1989), A review of the effects of transactional whole-body vibration on continuous manual control performance. J. of Sound and Vibration, 133, pp. 55-115.

3. Cho, Z.H., Chung, S.C., Lim, and Wong, E.K. (1998), Effects of the acoustic noise of the gradient systems on MRI: a study on auditory, motor, and visual cortices. Magn Reson Med, 39, pp. 331-335.

4. Smith, A.P. (1991), Noise and aspects of attention. Brit. J. of Psychology, 82, pp. 313-324.

5. Harris, C.S. and Shoenberger, R.W. (1980), Combined effects of broadband noise and complex waveform vibration on cognitive performance. Aviation Space and Environmental Medicine, 51(1), pp. 1-5.

6. Albery, W.B. (1989), The effect of sustained acceleration and noise on workload in human operators. Aviation Space and Environmental Medicine, 60(10), pp. 943-948.

7. Zimmermann, C.L. and Cook, T.M. (1997), Effects of vibration frequency and postural changes on human responses to seated whole-body vibration exposure. Int. Arch Occup. Environ. Health, 69(3), pp. 165-79.

8. Liu, J.Z., Kubo, M., Aoki, H., Liu, N., Kou, P.H., and Suzuki, T. (1995), A study on the difference of human sensation evaluation to whole-body vibration in sitting and lying postures. Appl. Human Sci., 14(5), pp. 219-26.

9. Hinz, B., Seidel, H., Menzel, G., and Bluthner, R. (2002), Effects related to random whole body vibration and posture on a suspended seat with and without backrest. J. of Sound and Vibration, 253(1), pp. 265-282.

10. Karlqvist, L., Wigaeus Tornqvist, E., Hagberg, M., Hagman, M., and Toomingas, A. (2002), Self-reported working conditions of VDU operators and associations with musculoskeletal symptoms: A cross-sectional study focusing on gender differences. International J. of Industrial Ergonomics, 30(4-5), pp. 277-294.

11. International Organization for Standardization (ISO). Mechanical vibration and shockevaluation of human exposure to whole-body vibration-part1: general requirements (Standard No. ISO;2631-1:1997). Geneva, Switzerland :ISO; 1997.

12. William Taylor, Brain Melloy, Pallavi Dharwada, Anand Gramopdhye, and Joe Toler (2004), The effect of static multiple sources of noise on the visual search component of human inspection. International J. of Industrial Ergonomics, (3), pp. 195-207. 
13. Bengtsson, K., Persson Waye, and Kjelberg, A. (2004), Evaluations of effects due to lowfrequency noise in a low demanding work situation. J. of Sound and Vibration, 278(1-2), pp. 83-99.

14. Pawlaczyk-Luszczynska, M., Dudarewicz, A., Waszkowska, M., and Sliwinska-Kowalska, M. (2003), Assessment of annoyance from low frequency and broadband noises. Int. J. Occup. Med. Environ. Health, 16(4), pp. 337-43.

15. Pawlaczyk-Luszczynska, M., Dudarewicz, A., Waszkowska, M., Szmczak, W., Kamedula, M., and Sliwinska-Kowalska, M. (2004), The effect of low frequency noise on human mental performance. Med. Pr., 55(1), pp. 63-74.

16. Levine, M.E. and Stern, R.M. (2002), Spatial task performance, sex differences, and motion sickness susceptibility. Percept. Mot. Skills, 95(2), pp. 425-31.

17. Guedry, F.E.Jr., Benson, A.J., and Moore, H.J. (1982), Influence of a visual display and frequency of whole-body angular oscillation on incidence of motion sickness. Aviation Space and Environmental Medicine, 53(6), pp. 564-569.

18. Sherwood, N. and Griffin, M.J. (1990), Effects of whole-body vibration on short-term memory. Aviation Space and Environmental Medicine, 61(12), pp. 1092-1097.

19. Kato, K. and Hanai, T. (1998), The effect of backrest angles on discomfort caused by foreand-aft back vibration. Ind. Health, 36(2), pp. 107-111.

20. Village, J., Morrison, J.B., and Leong, D.K. (1989), Whole body vibration in underground load haul-dump vehicles. Ergonomics, 32(10), pp. 1167-1183.

21. Well, M.J. and Griffin M.J. (1984), Benefits of helmet-mounted display image stablisation under whole-body vibration. Aviation Space and Environmental Medicine, 55(1), pp. 1318.

22. Griffin, M.J. and Hayward, R.A. (1994), Effects of horizontal whole-body vibration on reading. Applied Ergonomics, 25(3), pp. 165-169.

23. Corbridge, C. and Griffin, M.J. (1991), Effects of vertical vibration on passenger activities: Writing and Drinking. Ergonomics, 1991, 34(10), pp. 1313-1332. 